\title{
Síndrome de deleção 22q11.2: compreendendo o CATCH22
}

\author{
22q11.2 deletion syndrome: catching the $\mathrm{CATCH} 22$
}

\section{Rafael Fabiano M. Rosa ${ }^{1}$, Paulo Ricardo G. Zen², Tatiana Roman ${ }^{3}$, Carla Graziadio ${ }^{4}$, Giorgio Adriano Paskulin ${ }^{5}$}

\section{RESUMO}

Objetivo: Realizar uma revisão dos aspectos históricos, epidemiológicos, clínicos, etiológicos e laboratoriais da síndrome de deleção 22q11.2, salientando-se a importância e as dificuldades do seu diagnóstico.

Fontes de dados: Pesquisa nas bases de dados Medline, Lilacs e SciELO, além da Internet e capítulos de livros em inglês, acerca de publicações feitas entre 1980 e 2008. Para isso, utilizaram-se os descritores "22q11", "DiGeorge”, "Velocardiofacial" e "CATCH22".

Síntese dos dados: A síndrome de deleção 22q11.2, também conhecida como síndrome de DiGeorge ou velocardiofacial, foi identificada no começo da década de 1990. A microdeleção 22q11.2 é considerada uma das síndromes de microdeleção genética mais frequentes em seres humanos. Caracteriza-se por um espectro fenotípico bastante amplo, com mais de 180 achados clínicos já descritos do ponto de vista físico e comportamental. Contudo, nenhum achado é patognomônico ou mesmo obrigatório. A maioria dos pacientes apresenta uma deleção pequena, detectada somente por técnicas de genética molecular, como a hibridização in situ fluorescente. Apresenta padrão de herança autossômico dominante, ou seja, indivíduos acometidos apresentam um risco de $50 \%$ de transmiti-la a seus filhos.

Conclusões: Pacientes com a síndrome de deleção 22q11.2 frequentemente necessitam, ao longo de suas vidas, de um grande número de intervenções médicas e hospitalizações. O diagnóstico precoce é fundamental para a adequada avaliação e manejo clínico dos indivíduos e seus familiares.

Instituições: Universidade Federal de Ciências da Saúde de Porto Alegre (UFCSPA) e Complexo Hospitalar Santa Casa de Porto Alegre (CHSCPA), Porto Alegre, RS, Brasil

${ }^{1}$ Geneticista Clínico da UFCSPA e CHSCPA; Mestre em Patologia pela UFCSPA, Porto Alegre, RS, Brasil

${ }^{2}$ Geneticista Clínico da UFCSPA e CHSCPA; Doutor em Patologia pela UFCSPA; Professor Adjunto da Disciplina de Genética Clínica da UFCSPA, Porto Alegre, RS, Brasil

${ }^{3}$ Bióloga; Doutora em Genética e Biologia Molecular pela Universidade Federal do Rio Grande do Sul (UFRGS); Professora Adjunta do Departamento de Genética da UFRGS, Porto Alegre, RS, Brasil

${ }^{4}$ Geneticista Clínica da UFCSPA e CHSCPA; Mestre em Genética e Biologia Molecular pela UFRGS; Professora-assistente da Disciplina de Genética Clínica da UFCSPA, Porto Alegre, RS, Brasil
Palavras-chave: síndrome velocardiofacial; síndrome de DiGeorge; cromossomos humanos; hibridização in situ; aconselhamento genético.

\section{ABSTRACT}

Objective: To review historical, epidemiological, clinical, etiological and laboratorial aspects of the 22q11.2 deletion syndrome, highlighting the importance of the diagnosis and its difficulties.

Data sources: MedLine, Lilacs e SciELO databases, as well as internet and book chapters written in English, were searched for the period of 1980-2008, with the following descriptors "22q11", "DiGeorge", "Velocardiofacial" and "CATCH22".

Data synthesis: 22q11.2 deletion syndrome, also known as DiGeorge or velocardiofacial syndrome, was identified in the beginning of the 1990 decade. The 22q11.2 microdeletion is one of the most common human genetic microdeletion syndromes. It is characterized by a very broad phenotypic spectrum. More than 180 physical and behavioral clinical findings have already been described. However, none of them is characteristic or essential to diagnosis. The majority of the patients present a small deletion only detected by molecular genetic techniques as the fluorescent in situ hybridization. The deletion segregates in the families with an autosomal dominant pattern of inheritance, so the recurrence risk in the families is $50 \%$.

Conclusions: Individuals with 22q11.2 deletion syndrome have a great possibility to undergo medical interventions and hospitalizations throughout their lives. Early

${ }^{5}$ Geneticista Clínico da UFCSPA e CHSCPA; Citogeneticista; Doutor em Genética e Biologia Molecular da UFRGS; Professor-associado da Disciplina de Genética Clínica da UFCSPA, Porto Alegre, RS, Brasil

Endereço para correspondência:

Giorgio Adriano Paskulin

Rua Sarmento Leite, 245, sala 403 - Centro

CEP 90050-170 - Porto Alegre/RS

E-mail: paskulin@ufcspa.edu.br

Recebido em: 17/7/08

Aceito em: 19/10/08 
diagnosis is essential for the evaluation and clinical management of the patients and their families.

Key-words: velocardiofacial syndrome; DiGeorge syndrome; human chromosomes; in situ hybridization; genetic counseling.

\section{Introdução}

Considerando-se quão comum e variável é a síndrome de deleção 22q11.2 (SD22q11) (OMIM \#188400 / \#192430(1)), não é de se surpreender que tenha sido descrita de forma independente em diferentes momentos e de formas diversas em várias partes do mundo. Consequentemente, a SD22q11 recebeu vários nomes, dando a falsa impressão de que existem diferentes doenças associadas à deleção 22q11.2. Provavelmente, sua primeira descrição na literatura médica foi realizada por Sedlačkova, em 1955, uma foniatra de Praga que relatou um grupo de pacientes com voz anasalada e diminuição da mímica facial. Depois disso, em 1968, o cardiologista pediátrico Robert Strong descreveu uma família na qual a mãe e seus três filhos apresentavam arco aórtico à direita, dismorfismo facial e déficit cognitivo. Angelo DiGeorge, um endocrinologista pediátrico, relatou, logo a seguir, três crianças com deficiência imune letal de células $\mathrm{T}$ associada à hipoplasia das paratireoides. Na época, ele atribuiu esses achados a uma anormalidade do desenvolvimento do terceiro e quarto arcos branquiais e, nos casos subsequentes, notou uma associação com anomalias do arco aórtico. Em 1969, Cayler descreveu uma série de pacientes com anomalias cardíacas conotruncais e face assimétrica ao choro, enquanto Kinouchi et al relataram, no Japão, em 1976, uma síndrome caracterizada por cardiopatia congênita e aparência facial típica à qual denominaram "síndrome da anomalia facial conotruncal”. Em 1978, Shprintzen descreveu 12 indivíduos com um quadro de cardiopatia congênita, voz anasalada com anomalias de palato, aparência facial característica e dificuldades de aprendizagem. Na época, ele usou o termo "síndrome velocardiofacial" para caracterizar o quaro, que também ficou conhecido como síndrome de Shprintzen ${ }^{(2)}$.

$\mathrm{O}$ achado de um rearranjo cromossômico não balanceado envolvendo os cromossomos 20 e 22 em quatro pacientes de uma mesma família com a sequência de DiGeorge ${ }^{(3)}$ foi a base para identificar a microdeleção 22q11.2 nos anos subsequentes ${ }^{(4)}$. Alguns médicos têm a impressão equivocada de que as síndromes anteriormente descritas são doenças diferentes, causadas pela deleção 22q11.2. Contudo, todas elas representam a mesma condição, com uma expressão fenotípica altamente variável ${ }^{(2,5)}$. Em um esforço para unificar esse grande número de doenças relacionadas à deleção 22q11.2, Wilson et al ${ }^{(6)}$ propuseram o acrônimo CATCH22 (Conotruncal heart defect, Abnormal face, T-cell deficiency, Clefting, e Hypocalcemia, decorrentes de uma anormalidade no cromossomo 22). Entretanto, tal acrônimo foi rejeitado por muitos geneticistas clínicos devido à conotação negativa associada ao termo "catch-22" (traduzido para o português como "ardil22”), do romance de Joseph Heller de $1962^{(7)}$, que significava uma situação de perdedor. Assim, optou-se inicialmente pelo uso do termo síndrome de DiGeorge/Velocardiofacial, mas, em 1998, Bassett et al sugeriram o termo síndrome de deleção 22q11.2, designação utilizada até hoje ${ }^{(8)}$.

\section{Prevalência}

Apesar de não existirem estudos que confirmem a prevalência da SD22q11 ao nascimento, várias estimativas foram publicadas. Em parte, existe um problema nesse cálculo, pois a condição possui múltiplos nomes e uma variabilidade clínica muito grande. A frequência inicialmente sugerida de 1 em 4 mil indivíduos baseava-se no diagnóstico da sequência de DiGeorge. Entretanto, sabe-se hoje que a maioria dos indivíduos com a SD22q11 não apresenta uma sequência de DiGeorge verdadeira e essa incidência é provavelmente subestimada. Estudos populacionais com pacientes com cardiopatia congênita têm estimado prevalências que oscilam de 1 em cada 4 mil a 6 mil nascidos vivos ${ }^{(9-10)}$. Contudo, talvez a melhor estimativa de frequência para SD22q11 tenha sido calculada a partir de um estudo prospectivo que mostrou que $8,1 \%$ de todos os indivíduos com fenda palatina (incluindo fenda submucosa) apresentam a síndrome. A frequência de fenda palatina na população, em geral, é de aproximadamente 7,7 a cada mil indivíduos, o que leva a uma estimativa populacional de SD22q11 de cerca de um em 2 mil indivíduos. Contudo, sua prevalência ao nascimento é certamente maior, pois alguns bebês acabam morrendo ainda nos primeiros dias de vida devido a anormalidades cardíacas graves e/ou a sequências de malformações secundárias incompatíveis com a vida, como as sequências de Potter e de holoprosencefalia ${ }^{(5)}$.

\section{Manifestações clínicas}

A SD22q11 se caracteriza por um espectro fenotípico bastante amplo, com efeitos pleiotrópicos que resultam no acometimento de praticamente todos os órgãos e/ou 
sistemas. Mais de 180 achados clínicos, tanto físicos como comportamentais, têm sido relatados, incluindo anormalidades craniofaciais, oftalmológicas, otorrinolaringológicas, odontológicas, alimentares, gastrintestinais, neurológicas, de desenvolvimento psicossocial e de função cognitiva, psiquiátricas, autoimunes, hematológicas, imunológicas, endocrinológicas, vasculares, músculo-esqueléticas e geniturinárias ${ }^{(2,11-12)}$. Nenhuma dessas, contudo, ocorre com $100 \%$ de frequência, indicando não existirem manifestações patognomônicas ou obrigatórias para a síndrome ${ }^{(5,13)}$, o que dificulta o seu diagnóstico clínico. Entretanto, algumas delas são cardinais e deveriam levar a um alto índice de suspeita, como a presença de fenda palatina e a sequência de Pierre-Robin ${ }^{(5)}$. A SD22q11 também se associa frequentemente a defeitos cardíacos congênitos, especialmente do tipo conotruncal (que envolvem as vias de saída do coração, como a interrupção do arco aórtico e o truncus arteriosus $)^{(2,14)}$. Esses defeitos representam a principal causa de óbito em indivíduos com a SD22q11 (>90\% dos casos $)^{(11)}$, com ocorrência especialmente nos primeiros meses de vida, e parece estar associada à gravidade das lesões cardíacas e à presença, nesses indivíduos, de anormalidades extracardíacas ${ }^{(15)}$. Achados faciais se caracterizam principalmente por: a) aumento do comprimento vertical da face à custa, especialmente, de um excesso maxilar vertical; b) hipertelorismo (aumento da distância interpupilar); c) fendas palpebrais estreitas e oblíquas para cima; d) aumento da altura do nariz, com base e narinas pequenas, e um enchimento sobre a ponte, fazendo com que apresente um formato tubular ou cilíndrico; e) redundância das pálpebras superiores (booding) e retrognatia secundárias a uma anormalidade do ângulo da base do crânio, que se mostra mais obtuso; isso faz com que a fronte se localize mais anteriormente e a articulação temporomandibular, em posição mais posterior do que o habitual; e f) anormalidades menores de orelhas, em especial sobredobramento das hélices. Contudo, esses achados podem ser sutis, especialmente durante os primeiros anos de vida ${ }^{(12,14,16)}$, e sofrerem influência da origem étnica do paciente (por exemplo, podem ser menos perceptíveis em indivíduos da raça negra $)^{(17)}$, o que pode dificultar muito a identificação da condição. Por outro lado, Thomas e Graham ${ }^{(12)}$ destacam que a aparência facial dos pacientes tende a se acentuar com a idade. Além disso, outros achados frequentes, como distúrbios de fala e de aprendizagem, serão evidenciados somente mais tarde, durante a infância ${ }^{(18)}$. Algumas anormalidades em órgãos abdominais, especialmente renais, também podem não ser evidentes até a realização de um exame de imagem como o ultrassom ${ }^{(14)}$. Outras alterações frequentemente observadas em pacientes com a SD22q11 incluem os transtornos comportamentais (em especial a psicose) e a hipocalcemia (ver Tabela 1). Mas, como se pode observar na Tabela 1, a frequência de certos achados, considerados algumas vezes característicos, varia de acordo com a faixa etária dos pacientes estudados ${ }^{(11,19-21)}$. Cohen $e t$ al ${ }^{(20)}$ encontraram diferença significativa na frequência de certos achados clínicos entre pacientes com SD22q11 de diferentes idades. Anomalias de palato, dificuldades de aprendizagem, transtornos comportamentais e dismorfismos faciais estiveram mais presentes em adultos, ao passo que as cardiopatias congênitas foram mais observadas nas crianças. Isso pode ter alguma relação com os critérios de seleção das amostras e metodologias empregadas nos estudos, além da gravidade de certos defeitos, como as cardiopatias congênitas.

Os pacientes com a SD22q11 podem apresentar achados clínicos que se sobrepõem ao de outras doenças genéticas conhecidas, como as síndromes de Noonan ${ }^{(22)}$, Kousseff( ${ }^{(23)}$, Opitz G/BBB ${ }^{(24)}$, Goldenhar ${ }^{(25)}$ e a associação CHARGE ${ }^{(26)}$. Entretanto, esses indivíduos não devem ser designados, por exemplo, como portadores de síndrome de Opitz G/BBB devido a uma deleção 22q11.2, pois isso sugere incorretamente que eles não apresentam a SD22q11, o que pode deixar tanto familiares como médicos confusos. Em casos raros, no entanto, existe a possibilidade de certos indivíduos apresentarem, concomitantemente, a SD22q11 e outra doença genética. Relatos da associação, por exemplo, da SD22q11 com a síndrome de Down são encontrados na literatura ${ }^{(27)}$, mas são incomuns.

A maioria dos pacientes com a SD22q11 é identificada pela presença de um defeito cardíaco congênito maior, hipocalcemia e imunodeficiência no período neonatal, por se consultarem em clínicas ou centros de anormalidades craniofaciais que trabalham com fenda palatina ou por terem dificuldades de linguagem e de aprendizado quando alcançam a idade escolar ${ }^{(5,28)}$. De 50 a $75 \%$ dos pacientes apresentariam sinais precoces de uma malformação congênita maior que poderiam auxiliar na realização do seu diagnóstico ainda durante a infância ${ }^{(29)}$. Assim, dependendo da idade e dos problemas apresentados por esses pacientes, uma avaliação multidisciplinar é frequentemente necessária ${ }^{(2,12,28,30-32)}$, envolvendo especialidades como Pediatria, Genética Médica, Cardiologia, Otorrinolaringologia, Cirurgia Plástica, Imunologia, Endocrinologia e Psiquiatria. A Tabela 2 sumariza uma série de 
Tabela 1 - Frequência de características clínicas descritas em pacientes com a SD22q11 em diferentes estudos. Observar as diferenças entre os achados fenotípicos de acordo com a idade

\begin{tabular}{|c|c|c|c|c|c|}
\hline & $\begin{array}{l}\text { Ryan } \\
\text { et al, } \\
1997\end{array}$ & $\begin{array}{c}\text { McDonald- } \\
\text { McGinn et al, } \\
1999\end{array}$ & $\begin{array}{l}\text { Cohen } \\
\text { et al, } \\
1999\end{array}$ & $\begin{array}{c}\text { Óskarsdóttir } \\
\text { et al, } \\
2005\end{array}$ & $\begin{array}{c}\text { Bassett } \\
\text { et al, } \\
2005\end{array}$ \\
\hline Tamanho amostral (N) & 558 & 250 & 126 & 100 & 78 \\
\hline N - Idade & $\begin{array}{c}473:<18 \text { anos } \\
61:>18 \text { anos }\end{array}$ & $\begin{array}{c}140: \leq 5 \text { anos } \\
80: 6-16 \text { anos } \\
30:>16 \text { anos }\end{array}$ & 126: $\geq 18$ anos & $100: \leq 19$ anos & $78: \geq 17$ anos \\
\hline \multicolumn{6}{|l|}{ Achados clínicos (\%) } \\
\hline Cardiopatia congênita & 75 & 74 & 30 & 64 & 26 \\
\hline RDNPM & 68 & ND & ND & 96 & ND \\
\hline Hipocalcemia & 60 & 49 & 15 & 16 & 64 \\
\hline Retardo de crescimento & 36 & 41 & ND & ND & 21 \\
\hline Anomalias renais & 36 & 37 & ND & 2 & 26 \\
\hline Déficit auditivo & 33 & 39 & ND & ND & 28 \\
\hline Insuficiência velofaríngea & 32 & 27 & 47 & 68 & 42 \\
\hline Crises convulsivas & 21 & ND & ND & ND & 40 \\
\hline Agenesia/hipoplasia de timo & 17 & ND & ND & 91 & 10 \\
\hline Atraso de fala & 11 & ND & ND & 92 & ND \\
\hline Transtornos psiquiátricos & 9 & ND & 36 & 20 & 58 \\
\hline Fenda palatina & 9 & 11 & ND & ND & 31 \\
\hline Escoliose & 3 & 2 & ND & 9 & 47 \\
\hline Membrana laríngea & 1 & ND & 2 & ND & ND \\
\hline Trombocitopenia & ND & ND & 12 & ND & 28 \\
\hline Hipotireoidismo & 1 & ND & 1 & ND & 21 \\
\hline Estrabismo & ND & 13 & ND & ND & 15 \\
\hline
\end{tabular}

${ }^{*}$ RDNPM: retardo de desenvolvimento neuropsicomotor; ND: não determinado ou ausente.

avaliações e cuidados importantes no manejo de pacientes com a SD22q11.

\section{Etiologia}

A maioria dos pacientes com a SD22q11 apresenta uma deleção de cerca de 3 milhões de pares de base $(\mathrm{Mb})$ na região 11.2 do braço longo do cromossomo 22 , que permanece inalterada durante a transmissão de pai para filho. Em 7 a $8 \%$ dos casos conhecidos, existe uma deleção de $1,5 \mathrm{Mb}$ e, em 2 a $3 \%$, rearranjos menores dentro da região crítica de $3 \mathrm{Mb}$ em 22q11.2. Sabe-se, hoje, que o braço longo do cromossomo 22 apresenta um arranjo não usual, com regiões de repetições de baixo número de cópias (Low Copy Repeats, LCRs) essencialmente idênticas, que predispõe a região q11.2 à deleção. Essa deleção é causada por um evento de recombinação homóloga durante o primeiro estágio da prófase da meiose, na maioria das vezes secundária a um erro de pareamento das sequências de DNA entre dois cromossomos 22 (intercromossômica), de forma que a $L C R$ proximal de um deles reconhece a distal do outro. Como os cromossomos estão proximamente alinhados, acontece um crossing-over desigual, fazendo com que um dos 
Tabela 2 - Avaliações e cuidados importantes em pacientes com síndrome de deleção 22q11.2

\section{Crescimento e alimentação}

- Avaliar possíveis problemas alimentares como refluxo gastresofágico, distúrbios da deglutição, vômitos e constipação.

- A melhor forma de avaliação de distúrbios da deglutição envolve o uso da endoscopia.

- A radiografia contrastada pode ser utilizada em crianças maiores quando houver suspeita de anormalidades vasculares que estejam comprimindo o esôfago e podem ser confirmadas por ressonância magnética.

\section{Neurológicas e comportamentais}

- A avaliação do desenvolvimento neuropsicomotor, da fala e linguagem deve ser feita a partir do período neonatal

- A nasofibrobroncoscopia é o melhor método para avaliar causas de hipernasalidade, como anomalias e disfunção palatinas

- A avaliação psiquiátrica está indicada em idade pré-escolar ou escolar diante de alterações comportamentais (sinais de transtorno de déficit de atenção com hiperatividade ou transtorno obsessivo compulsivo). É recomendada também na puberdade.

- Dosagens séricas de cálcio devem ser obtidas durante episódios de crises convulsivas (para excluir hipocalcemia).

- Exames de imagem cerebral, particularmente ressonância nuclear magnética, podem identificar anormalidades como derrames (infartos cerebrais) e atrofia cortical.

- A avaliação por ressonância magnética da coluna é indicada quando se suspeita de alterações como medula presa ou meningocele.

\section{Otorrinolaringológicas}

- $\quad \mathrm{Na}$ ausência de fenda palatina, o exame cuidadoso do palato deve ser feito para procurar alterações como úvula bífida ou hipoplásica, indicativas da possível presença de fenda palatina submucosa.

- Avaliações otológicas e audiométricas, incluindo audiometria de tronco cerebral, são recomendadas.

- Episódios frequentes e prolongados de otites médias devem ser também acompanhados por avaliações audiométricas.

\section{Cardiovasculares}

- A avaliação cardiológica, com ecocardiografia, deve ser sempre feita, mesmo na ausência de sintomas.

- A angioressonância pode ser utilizada na suspeita de anomalias vasculares cervicais e cerebrais. Quando não pode ser realizada (após cirurgia cardíaca com uso de grampos ou fios metálicos), a angiotomografia é recomendada. As artérias carótidas internas são frequentemente ectópicas nos pacientes com SD22q11 e podem se encontrar logo abaixo da mucosa faríngea, o que facilita complicações graves durante cirurgias da faringe.

\section{Endocrinológicas}

- Avaliação anual dos níveis séricos de cálcio é recomendada a todas as crianças e adultos afetados.

- Hipotireoidismo deve ser descartado em indivíduos com manifestações clínicas de função tireoidiana anormal.

- A avaliação de baixa estatura por endocrinologista visa descartar deficiência de hormônio de crescimento.

\section{Imunológicas e hematológicas}

- Análise laboratorial da função imune, com contagem de linfócitos e avaliação da resposta humoral, é indicada em indivíduos com história de infecções crônicas de vias aéreas superiores e inferiores.

- Crianças com anormalidades imunes não devem receber vacinas com vírus vivos atenuados. Algumas podem não apresentar soroconversão após a inoculação das vacinas, podendo necessitar de aplicações adicionais.

- Indicam-se hemocomponentes irradiados e com sorologia negativa para CMV naqueles com deficiência imune.

- Avaliação hematológica deve ser feita em casos de distúrbios da coagulação. 
Oftalmológicas

- Avaliação oftalmológica, com exame de fundo de olho, deve ser sempre realizada no momento do diagnóstico.

Geniturinárias

- Ultrassonografia abdominal deve ser feita ao diagnóstico para identificar anomalias renais.

\section{Ortopédicas}

- A radiografia da coluna dorsal (período neonatal) e da coluna cervical (a partir dos quatro anos) deve ser feita para avaliar a presença de anomalias vertebrais.

Fonte: Shprintzen ${ }^{(5)}$; Kobrynski e Sullivan ${ }^{(32)}$.

cromossomos 22 sofra deleção e o outro receba material cromossômico extra (apresente duplicação). Em aproximadamente $10 \%$ dos casos, essa perda de material genético ocorre intracromossomialmente, devido a um pareamento entre as $L C R$ s de um mesmo cromossomo $22^{(5,32)}$.

O sequenciamento da região frequentemente deletada de $3 \mathrm{Mb}$ revelou a presença de aproximadamente 30 genes, entre os quais incluem-se o UFD1L (Ubiquitin Fusion Degradation 1-Like), o TBX1 (T-BOX 1) e o TUPLE1 (TUP-Like Enhancer of split gene-1 ou HIRA), expressos nas células derivadas da crista neural e possíveis responsáveis pelos achados clínicos observados na SD22q11 (32-33). Essas células têm grande importância no desenvolvimento do septo conotruncal do coração $^{(34)}$ e as malformações dessa região são frequentes em pacientes com a SD22q11. Apesar de a análise de modelos animais apresentar limitado sucesso ${ }^{(33)}$, sugere-se que o gene TBX1 seja crítico para os achados clínicos da síndrome ${ }^{(5,32)}$. Mutações nesse gene têm sido encontradas em pacientes com a síndrome e sem a microdeleção 22q11.2, quando investigadas pelo exame de hibridização in situ fluorescente (FISH) ${ }^{(35)}$. Por sua vez, o gene COMT (Catechol-O-Methyltransferase) é fortemente associado ao fenótipo psiquiátrico. Sua haploinsuficiência resulta em inabilidade de degradar dopaminas e níveis elevados dessas substãncias têm sido implicados em uma variedade de transtornos comportamentais, como o espectro obsessivo-compulsivo, a psicose e o transtorno de déficit de atenção e hiperatividade (TDAH), frequentes em pacientes com a SD22q11 $1^{(5,32)}$.

Desse modo, a grande variabilidade clínica, tanto intra como interfamiliar ${ }^{(12,36)}$, tem feito com que as correlações genótipo-fenótipo sejam difíceis ${ }^{(30)}$. Diferenças fenotípicas são observadas mesmo entre gêmeos monozigóticos ${ }^{(37)}$. Ao contrário de outras síndromes de microdeleção cromossômica, há também uma falta de correlação entre o tamanho da deleção e a gravidade da doença ${ }^{(12,36)}$. A grande complexidade e heterogeneidade genéticas tem dificultado a determinação definitiva do(s) gene(s) crítico(s) para a SD22q11 (29).

\section{Diagnóstico laboratorial}

Estudos citogenéticos com o uso do cariótipo de alta resolução revelam que menos de $15 \%$ dos pacientes apresentam deleções visíveis na região 22q11 ${ }^{(38)}$. Essa técnica, diferentemente do cariótipo convencional, permite que os cromossomos sejam analisados em uma etapa mais precoce da mitose, na pró-metáfase, na qual estão menos condensados e com um número maior de bandas cromossômicas, ou seja, mais ricos em detalhes ${ }^{(39)}$. Uma pequena porcentagem $(<1 \%)$ tem rearranjos cromossômicos, como translocações envolvendo a região q11 do cromossomo $22^{(30)}$. Contudo, a maioria dos pacientes apresenta uma deleção bastante pequena (microdeleção) em 22q11.2, detectável somente pelo FISH, uma técnica que integra a utilização da citogenética clássica com a genética molecular, por meio do uso de sondas de DNA marcadas com material fluorescente que identificam regiões específicas do genoma ${ }^{(12-}$ ${ }^{13,40)}$. As duas sondas usualmente disponíveis para essa análise são a N25 (que se hibridiza em D22S75, localizada dentro da região comumente deletada na SD22q11) e TUPLE 1 (que se liga a todo o gene TUPLE 1 e parte do DNA localizado junto às suas extremidades). $\mathrm{O}$ índice de detecção da microdeleção 22q11.2 parece ser semelhante para ambas. Para essa técnica, utiliza-se também uma sonda de controle, a ARSA, que se hibridiza no loco 22q13.3, onde está localizado o gene da enzima lisossomal arilsulfatase $\mathrm{A}^{(30)}$ (Figura 1). Os reagentes das sondas hibridizadas fluorescem com intensidade moderada a brilhante, sendo que, em núcleos de células normais, eles geralmente aparecem como dois pares de sinais distintos, um vermelho (N25 ou TUPLE 1) e um verde (ARSA). Em uma metáfase normal, a sonda se apresenta tipicamente com pequenos sinais, um em cada cromátide de cada cópia do cromossomo 22.

Mais de 90\% dos pacientes com a SD22q11 tem uma deleção intersticial no braço longo do cromossomo 22 detectável por técnicas correntes de citogenética e de $\mathrm{FISH}^{(13)}$. Contudo, deve-se ter em mente que um resultado negativo a partir dessas análises não exclui a presença de anormalidades na região 
22q11.2, pois alguns pacientes $(<5 \%)$ podem apresentar deleções menores ou mutações de ponto dentro de genes específicos detectadas somente por técnicas moleculares, como o sequenciamento ${ }^{(30)}$. Relatos de mosaicismo para deleção 22q11.2, tanto em células somáticas ${ }^{(41)}$ como germinativas ${ }^{(42)}$, também existem. Apesar de raros, alguns autores acreditam que sejam, provavelmente, subdiagnosticados ${ }^{(36)}$.

Atualmente, outras técnicas de análise molecular são utilizadas para detectar microdeleções 22q11.2, como o ensaio pela Hibridização Genômica Comparativa (Comparative Genomic Hybridization, $C G H)^{(43)}$ e a Multiplex Ligation-dependent Probe Amplification $(M L P A)^{(44)}$. A avaliação molecular de polimorfismos de microssatélite também é um possível método para o diagnóstico dessa síndrome, com várias consequências práticas. Primeiro, a análise genotípica baseada na reação em cadeia da polimerase (PCR) faz o procedimento experimental ser mais rápido, barato e fácil; segundo, a alta informatividade desse tipo de marcador faz com que a deteç̧ão de hemizigosidade seja muito mais simples em comparação a outros marcadores, como os RFLPs (Restriction Fragment Length Polymorphisms). Finalmente, a perda da heterozigosidade detectada por esses marcadores poderia ser usada como ferramenta real de diagnóstico em pacientes suspeitos de SD22q11. Gioli-Pereira et al, pesquisando polimorfismos de nucleotídeo único (Single Nucleotide Polymorphisms, SNPs) também localizados em 22q11.2, verificaram que, na população brasileira, esses marcadores são eficientes para determinar a perda de heterozigosidade em até $92,9 \%$ dos $\operatorname{casos}^{(45)}$.

Assim, ao suspeitar de SD22q11, o primeiro passo para o diagnóstico é realizar a avaliação citogenética por cariótipo de alta resolução. No caso de um exame normal, seguir a avaliação pela técnica de FISH para microdeleção 22q11.2. Como já visto, o uso combinado dessas duas técnicas é capaz de identificar quase a totalidade dos $\operatorname{casos}^{(13)}$. A maior parte dos demais exames moleculares é utilizada somente em nível de pesquisa. O diagnóstico pela PCR, apesar de suas facilidades, ainda não se encontra disponível comercialmente ${ }^{(32)}$. Contudo, não se pode esquecer que o fenótipo da SD22q11 é observado em outras condições, como em casos de deleções do braço curto do cromossomo 10 e do braço longo do cromossomo 4, da síndrome alcoólica fetal e da embriopatia pelo ácido retinoico ${ }^{(2,12)}$.

\section{Padrão de herança e aconselhamento genético}

A deleção 22 q11.2 pode ser tanto herdada ( 8 a $28 \%$ dos casos), como decorrente de uma deleção nova (mutação de

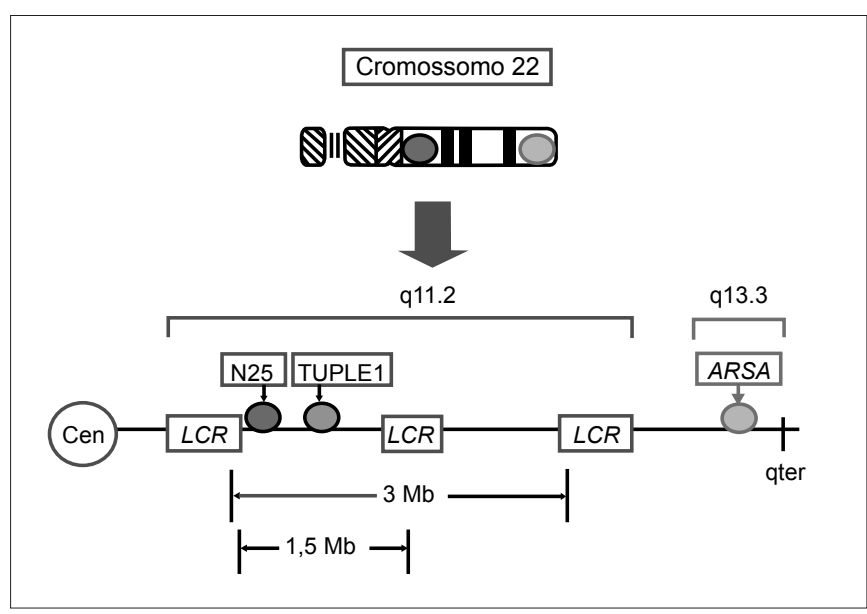

Figura 1 - Ideograma mostrando os locais de ligação das sondas de DNA N25 e TUPLE1 na região q11.2 e da sonda $A R S A$ na região q13.3 do cromossomo 22 utilizadas na técnica de FISH para deteç̧ão da microdeleção 22q11.2.

novo $)^{(11,46)}$. Nos casos familiares, parece haver um predomínio de relatos de herança materna sobre a paterna. Isso se deve, provavelmente, a fatores socioculturais, pois mulheres com a SD22q11 se reproduzem mais do que homens com a mesma síndrome ${ }^{(29)}$. A deleção 22q11.2 segrega nas famílias com um padrão de herança autossômico dominante, ou seja, indivíduos com a deleção apresentam um risco de $50 \%$ de a transmitirem a seus filhos. Esse padrão de herança foi inicialmente suspeitado por Shprintzen et al em 1978, após observarem casos de síndrome velocardiofacial com transmissão de mãe para filha, e confirmado em 1985, com a descrição do primeiro caso de transmissão de pai para filho ${ }^{(47)}$.

Ambos os pais de um paciente com a SD22q11 devem ser testados para excluir a possibilidade de que um deles apresente a deleção ${ }^{(46)}$. Tal avaliação é particularmente importante se os mesmos ou outros membros da família consideram a possibilidade de terem outros filhos. Devido à variabilidade clínica da síndrome e à sutileza de alguns dos seus achados, um parente afetado pode não ser clinicamente identificado. Usualmente, esses indivíduos não apresentam malformações congênitas maiores, o que claramente representa um viés de seleção, pois são aqueles que sobrevivem a ponto de se reproduzirem ${ }^{(29)}$. Assim, esse teste é indicado mesmo em familiares aparentemente normais.

Se um paciente apresenta a deleção 22q11.2 e um cariótipo normal, recomenda-se o estudo dos pais por técnica de FISH. O risco de recorrência de um casal com uma criança afetada pela SD22q11 devido a uma mutação de novo é baixo, pois existe a possibilidade (pequena, mas ao mesmo tempo 
indeterminada) de que um dos pais apresente um mosaicismo para a deleção na sua linhagem germinativa ${ }^{(29)}$. Em poucos casos, a SD22q11 pode ser secundária a um rearranjo cromossômico, como uma translocação. Nesses casos, o cariótipo dos pais pode ajudar a identificar a origem da anormalidade cromossômica. Dependendo do tipo de alteração, os riscos de recorrência para um indivíduo afetado podem diferir dos $50 \%$ anteriormente descritos, podendo ou não aumentar as suas chances de apresentar uma prole afetada tanto pela SD22q11 como por outras anormalidades cromossômicas. Alguns indivíduos com fenótipo sugestivo da SD22q11 podem não apresentar uma deleção detectável pela técnica de FISH por serem portadores de uma mutação, por exemplo, em um único gene dentro da região 22q11.2, ou por apresentarem esse quadro clínico devido a uma alteração distinta da SD22q11.

Todas essas informações são essenciais para o adequado aconselhamento genético dos indivíduos afetados e de suas famílias. Entretanto, mesmo com acesso a todas elas, o aconselhamento genético ainda pode ser dificultado por problemas de aprendizagem e por transtornos comportamentais frequentemente presentes em indivíduos com a SD22q11 $11^{(12)}$.

\section{Diagnóstico pré-natal}

Atualmente, o diagnóstico pré-natal da SD22q11 pode ser oferecido a casais em risco com o objetivo de fornecer um diagnóstico acurado, informações prognósticas e aconselhamento genético apropriado ${ }^{(48)}$. A ultrassonografia fetal de alta resolução também é capaz de detectar um grande número de anomalias fetais, como malformações cardíacas e fenda palatina, que podem auxiliar na triagem dos pacientes que devem realizar o teste de FISH. A medida da translucência nucal tem valor limitado quando utilizada isoladamente ${ }^{(49)}$. Relatos recentes mostram que, durante o pré-natal, os exames

\section{Referências bibliográficas}

1. Online Mendelian Inheritance in Man, OMIM (TM) [homepage on the Internet]. McKusick-Nathans Institute for Genetic Medicine, Johns Hopkins University (Baltimore, MD) and National Center for Biotechnology Information, National Library of Medicine (Bethesda, MD) [cited 2007 Oct 8]. Available from: http:// www.ncbi.nlm.nih.gov/omim/

2. Robin NH, Shprintzen RJ. Defining the clinical spectrum of deletion $22 q 11.2$. J Pediatr 2005;147:90-6. sorológicos de triagem de segundo trimestre podem auxiliar nessa escolha. Gestantes com fetos portadores da SD22q11 apresentam diminuição nas dosagens séricas de alfafetoproteína (AFP), estriol não conjugado $\left(\mathrm{uE}_{3}\right)$ e gonadotrofina coriônica humana ( $\beta$ hCG), padrão semelhante ao observado em grávidas com fetos acometidos pela trissomia do cromossomo $18^{(50)}$.

\section{Importância do diagnóstico da SD22q11}

Pacientes com a SD22q11 são considerados indivíduos em risco, uma vez que podem necessitar, ao longo de suas vidas, de um grande número de intervenções médicas e hospitalizações ${ }^{(31,51)}$. Assim, o reconhecimento da síndrome não apenas permite identificar e tratar anormalidades associadas, mas também influencia no aconselhamento genético aos familiares ${ }^{(6,12,52)}$. Além disso, a presença de anormalidades orofaríngeas, laringobrônquicas, imunológicas, endócrinas, psiquiátricas e cardiovasculares, frequentes na SD22q11, pode levar a várias complicações clínicas tanto no momento da indução anestésica como durante e após a realização de procedimentos cirúrgicos ${ }^{(53)}$. Recentemente, houve relatos de que esses pacientes apresentam predisposição maior do que a população em geral para o desenvolvimento de certos tumores pediátricos, como o hepatoblastoma ${ }^{(54-55)}$.

Assim, o diagnóstico precoce desses pacientes é fundamental para a adequada avaliação e manejo clínico, tanto deles como de suas famílias. Contudo, a grande variabilidade clínica apresentada pela síndrome, associada ao fato de que técnicas diagnósticas sensíveis, como o FISH, são praticamente inexistentes em nosso meio, tem dificultado muito a sua identificação. Considerando-se a alta prevalência dessa síndrome na população e a repercussão que seu diagnóstico traz para a família dos indivíduos acometidos e para a sociedade em geral, torna-se oportuno o investimento de recursos com o objetivo de criar serviços e infraestruturas capazes de identificar e tratar os portadores dessa síndrome.

3. De La Chapelle A, Herva R, Koivisto M, Aula P. A deletion in chromosome 22 can cause DiGeorge syndrome. Hum Genet 1981;57:253-6.

4. Scambler PJ, Carey AH, Wyse RK, Roach S, Dumanski JP, Nordenskjold M et al. Microdeletions within 22q11 associated with sporadic and familial DiGeorge syndrome. Genomics 1991;10:201-6.

5. Shprintzen RJ. Velo-cardio-facial syndrome. In: Cassidy SB, Allanson J, editors. Management of genetic syndromes. New York: Wiley; 2005. p. 495-517. 
6. Wilson DI, Burn J, Scambler P, Goodship J. DiGeorge syndrome: part of CATCH 22. J Med Genet 1993;30:852-6.

7. Heller J. Catch-22. London: Jonathan Cape; 1962.

8. Bassett AS, Hodgkinson K, Chow EW, Correia S, Scutt LE, Weksberg R. 22q11 deletion syndrome in adults with schizophrenia. Am J Med Genet 1998;81:328-37.

9. Goodship J, Cross I, LiLing J, Wren C. A population study of chromosome $22 q 11$ deletions in infancy. Arch Dis Child 1998;79:348-51.

10. Botto LD, May K, Fernhoff PM, Correa A, Coleman K, Rasmussen SA et al. A population-based study of the 22q11.2 deletion: phenotype, incidence, and contribution to major birth defects in the population. Pediatrics 2003;112: 101-7.

11. Ryan AK, Goodship JA, Wilson DI, Philip N, Levy A, Seidel H et al. Spectrum of clinical features associated with interstitial chromosome 22q11 deletions: a European collaborative study. J Med Genet 1997;34:798-804.

12. Thomas JA, Graham JM Jr. Chromosome 22q11 deletion syndrome: an update and review for the primary pediatrician. Clin Pediatr (Phila) 1997;36:253-66.

13. Ardinger $\mathrm{R}$, Ardinger $\mathrm{H}$ [homepage on the Internet]. Velocardiofacial syndrome [cited 2009 Apr 30]. Available from: http://www.emedicine.com/ped/ topic2395.htm

14. Rosa RF, Pilla CB, Pereira VL, Flores JA, Golendziner E, Koshiyama DB et al. 22q11.2 deletion syndrome in patients admitted to a cardiac pediatric intensive care unit in Brazil. Am J Med Genet 2008;146A:1655-61.

15. Kyburz A, Bauersfeld U, Schinzel A, Riegel M, Hug M, Tomaske M et al. The fate of children with microdeletion 22q11.2 syndrome and congenial heart defect: clinical course and cardiac outcome. Pediatr Cardiol 2008;29: 76-83.

16. Digilio MC, Marino B, Giannotti A, Dallapiccola B. Search for $22 q 11$ deletion in non-syndromic conotruncal cardiac defects. Eur J Pediatr 1996;155:619-24.

17. McDonald-McGinn DM, Minugh-Purvis N, Kirschner RE, Jawad A, Tonnesen MK, Catanzaro JR et al. The 22q11.2 deletion in African-american patients: an underdiagnosed population? Am J Med Genet 2005;134:242-6.

18. Goldmuntz E, Clark BJ, Mitchell LE, Jawad AF, Cuneo BF, Reed L et al. Frequency of 22q11 deletions in patients with conotruncal defects. J Am Coll Cardiol 1998;32:492-8.

19. McDonald-McGinn DM, Kirschner R, Goldmuntz E, Sullivan K, Eicher P, Gerdes $\mathrm{M}$ et al. The Philadelphia story: the 22q11.2 deletion: report on 250 patients. Genet Couns 1999;10:11-24

20. Cohen E, Chow EW, Weksberg R, Bassett AS. Phenotype of adults with the 22q11 deletion syndrome: a review. Am J Med Genet 1999;86:359-65.

21. Bassett AS, Chow EW, Husted J, Weksberg R, Caluseriu O, Webb GD et al. Clinical features of 78 adults with 22q11 deletion syndrome. Am J Med Genet 2005;138:307-13.

22. Wilson DI, Britton SB, McKeown C, Kelly D, Cross IE, Strobel S et al. Noonan's and DiGeorge syndromes with monosomy 22q11. Arch Dis Child 1993;68:187-9.

23. Forrester S, Kovach MJ, Smith RE, Rimer L, Wesson M, Kimonis VE. Kousseff syndrome caused by deletion of chromosome 22q11-13. Am J Med Genet 2002;112:338-42.

24. McDonald-McGinn DM, Driscoll DA, Bason L, Christensen K, Lynch D, Sullivan $\mathrm{K}$ et al. Autosomal dominant "Opitz" GBBB syndrome due to a 22q11.2 deletion. Am J Med Genet 1995;59:103-13.

25. Derbent M, Yilmaz Z, Baltaci V, Saygili A, Varan B, Tokel K. Chromosome 22q11.2 deletion and phenotypic features in 30 patients with conotruncal heart defects. Am J Med Genet 2003;116A:129-35.

26. Devriendt K, Swillen A, Fryns JP. Deletion in chromosome region 22q11 in a child with CHARGE association. Clin Genet 1998;53:408-10.

27. Derbent M, Bikmaz YE, Yilmaz Z, Tokel K. Variable phenotype and associations in chromosome 22q11.2 microdeletion. Am J Med Genet 2006;140:659-60.

28. Oskarsdóttir S, Persson C, Eriksson BO, Fasth A. Presenting phenotype in 100 children with the 22q11 deletion syndrome. Eur J Pediatr 2005;164:146-53.

29. Swillen A, Vogels A, Devriendt K, Fryns JP. Chromosome 22q11 deletion syndrome: update and review of the clinical features, cognitive-behav- ioral spectrum, and psychiatric complications. Am J Med Genet 2000;97: 128-35.

30. McDonald-McGinn DM, Emanuel BS, Zackai EH [homepage on the Internet]. 22q11.2 deletion syndrome [cited 2007 Oct 10]. Available from: http://www. ncbi.nlm.nih.gov/bookshelf/br.fcgi?book=gene\&part=gr_22q11deletion

31. Greenhalgh KL, Aligianis IA, Bromilow G, Cox H, Hill C, Stait Y et al. 22q11 deletion: a multisystem disorder requiring multidisciplinary input. Arch Dis Child 2003;88:523-4.

32. Kobrynski LJ, Sullivan KE. Velocardiofacial syndrome, DiGeorge syndrome: the chromosome 22q11.2 deletion syndromes. Lancet 2007;370: 1443-52.

33. Srivastava D. Genetic assembly of the heart: implications for congenital heart disease. Annu Rev Physiol 2001;63:451-69.

34. Harris JA, Francannet C, Pradat P, Robert E. The epidemiology of cardiovascular defects, part 2: a study based on data from three large registries of congenital malformations. Pediatr Cardiol 2003;24:222-35.

35. Yagi H, Furutani Y, Hamada H, Sasaki T, Asakawa S, Minoshima S et al. Role of TBX1 in human del22q11.2 syndrome. Lancet 2003;362:1366-73.

36. Digilio MC, Angioni A, De Santis M, Lombardo A, Giannotti A, Dallapiccola B et al. Spectrum of clinical variability in familial deletion 22q11.2: from full manifestation to extremely mild clinical anomalies. Clin Genet 2003;63: 308-13.

37. Vincent MC, Heitz F, Tricoire J, Bourroillou G, Kuhlein E, Rolland M et al. 22q11 deletion in DGS/VCFS monozygotic twins with discordant phenotypes. Genet Couns 1999;10:43-9.

38. Driscoll DA, Spinner NB, Budarf ML, McDonald-McGinn DM, Zackai EH, Goldberg $\mathrm{RB}$ et al. Deletions and microdeletions of 22q11.2 in velo-cardio-facial syndrome. Am J Med Genet 1992;44:261-8.

39. Yunis JJ. New chromosome techniques in the study of human neoplasia. Hum Pathol 1981;12:540-9.

40. Stumm M, Tönnies H, Wieacker PF. Molecular cytogenetic techniques for the diagnosis of chromosomal abnormalities in childhood disease. Eur J Pediatr 1999;158:531-6.

41. Consevage MW, Seip JR, Belchis DA, Davis AT, Baylen BG, Rogan PK. Association of a mosaic chromosomal 22q11 deletion with hypoplastic left heart syndrome. Am J Cardiol 1996;77:1023-5.

42. Hatchwell E, Long F, Wilde J, Crolla J, Temple K. Molecular confirmation of germ line mosaicism for a submicroscopic deletion of chromosome 22q11. Am J Med Genet 1998;78:103-6.

43. Bar-Shira A, Rosner G, Rosner S, Goldstein M, Orr-Urtreger A. Arraybased comparative genome hybridization in clinical genetics. Pediatr Res 2006;60:353-8.

44. Vorstman JA, Jalali GR, Rappaport EF, Hacker AM, Scott C, Emanuel BS. MLPA: a rapid, reliable, and sensitive method for detection and analysis of abnormalities of 22q. Hum Mutat 2006;27:814-21.

45. Gioli-Pereira L, Pereira AC, Mesquita SM, Lopes AA, Krieger JE. PCR screening for 22q11.2 microdeletion: development of a new cost-effective diagnostic tool. Clin Chim Acta 2006;369:78-81.

46. Smith A, Robson L. Low frequency of inherited deletions of 22q11. Am J Med Genet 1999;85:513-4.

47. Williams MA, Shprintzen RJ, Goldberg RB. Male-to-male transmission of the velo-cardio-facial syndrome: a case report and review of 60 cases. J Craniofac Genet Dev Biol 1985;5:175-80.

48. Driscoll DA. Prenatal diagnosis of the 22q11.2 deletion syndrome. Genet Med 2001;3:14-8.

49. Donnenfeld AE, Cutillo D, Horwitz J, Knops J. Prospective study of 22q11 deletion analysis in fetuses with excess nuchal translucency. Am J Obstet Gynecol 2006;194:508-11.

50. Begleiter ML, Lund MM, Atherton AM, Buchholz JD, Ardinger HH. Maternal serum screening and 22q11.2 deletion syndrome. Am J Med Genet 2007;143:410-1.

51. Hopkin RJ, Schorry EK, Bofinger M, Saal HM. Increased need for medical interventions in infants with velocardiofacial (deletion 22q11) syndrome. J Pediatr 2000;137:247-9 
52. Goldberg R, Motzkin B, Marion R, Scambler PJ, Shprintzen RJ. Velocardio-facial syndrome: a review of 120 patients. Am J Med Genet 1993;45:313-9

53. Yotsui-Tsuchimochi H, Higa K, Matsunaga M, Nitahara K, Shono S. Anesthetic management of a child with chromosome 22q11 deletion syndrome. Paediatr Anaesth 2006;16:454-7.
54. Scattone A, Caruso G, Marzullo A, Piscitelli D, Gentile M, Bonadonna L et al. Neoplastic disease and deletion 22q11.2: a multicentric study and report of two cases. Pediatr Pathol Mol Med 2003;22:323-41.

55. McDonald-McGinn DM, Reilly A, Wallgren-Petterson C, Hoyme HE, Yang SP, Adam MP et al. Malignancy in chromosome 22q11.2 deletion syndrome (DiGeorge syndrome/velocardiofacial syndrome). Am J Med Genet 2006;140A:906-9. 